\title{
Metachronous infiltration of bone marrow due to breast cancer and multiple myeloma
}

\author{
Ahmet Peker ${ }^{1}$, Hakan Yarkıcı', Mehmet Can Uğur ${ }^{1}$, Harun Akar' ${ }^{1}$, Cengiz Ceylan², Dudu Solakoğlu Kahraman ${ }^{3}$ \\ ${ }^{1}$ Department of Internal Medicine, Tepecik Training and Research Hospital, Izmir, Turkey \\ ${ }^{2}$ Department of Hematology, Tepecik Training and Research Hospital, Izmir, Turkey \\ ${ }^{3}$ Department of Pathology, Tepecik Training and Research Hospital, İzir, Turkey
}

\begin{abstract}
Multiple primary tumors are rarely seen in clinical practice. Cases of metastatic breast cancer associated with multiple myeloma were rare in the literature. It is believed that simultaneously observed bone marrow involvement due to breast cancer and multiple myeloma is sporadic. We present a 49-year-old female patient with metastatic breast cancer who developed multiple myeloma during breast cancer treatment.
\end{abstract}

Keywords: Bone marrow involvement, breast cancer, multiple myeloma, metachronous malignancy

\section{Introduction}

Multiple myeloma is a malignant disease of plasma cells. It is a relatively rare disease. It forms $1 \%$ of all cancer cases and $10 \%$ of all hematological malignancies [1]. Other solid organ tumors rarely accompany multiple myeloma. Breast cancer is the most frequently seen cancer in women worldwide. Its relation with colon, vulva, lung, larynx, liver, uterus cancers has been identified in the literature [2]. A case with a history of breast cancer came to internal medicine clinic offering findings remarkable for multiple myeloma.

\section{Case Presentation}

A 49-year-old female patient with no significant history except hypertension came to her physician with a complaint of left breast mass and the patient underwent a tru-cut needle biopsy one year ago. A diagnosis of invasive ductal carcinoma exhibiting both estrogen- progesterone receptor positivity was established. PET CT demonstrated thoracic vertebral involvement. Clinically, the patient appeared to have a stage 4 breast carcinoma. She began a chemotherapeutic regimen of cyclophosphamide (600 $\left.\mathrm{mg} / \mathrm{m}^{2}\right)$, epirubicin $\left(60 \mathrm{mg} / \mathrm{m}^{2}\right)$ and 5-fluorouracil (500 $\left.\mathrm{mg} / \mathrm{m}^{2}\right)$. She received nine cycles of this regimen followed by the left modified radical mastectomy and lymph node dissection.

After surgery, the patient received two more cycles of chemotherapy. Since the patient stated that she had been fatigued and having palpitation, she came to internal medicine clinic in our hospital with concerns regarding these symptoms. The patient was electively admitted to our clinic for evaluation. Vital signs were blood pressure $130 / 85 \mathrm{~mm} / \mathrm{Hg}$, temperature $36.7^{\circ} \mathrm{C}$, respiratory rate: $18 / \mathrm{min}$, and heart rate: 78 beat $/ \mathrm{min}$. 
Cardiovascular and pulmonary examinations were within normal limits. ECG and chest x-ray were normal. Routine laboratory analyses were follows: hemoglobin $7.6 \mathrm{mg} / \mathrm{dL}$, white blood cells $5,400 / \mu \mathrm{L}$, platelet counts $234,000 / \mu \mathrm{L}$, erythrocyte sedimentation rate $84 \mathrm{~mm} / \mathrm{h}$, sodium $129 \mathrm{~mm} / \mathrm{L}$, potassium 4.68 $\mathrm{mm} / \mathrm{L}$, calcium $9.5 \mathrm{~mm} / \mathrm{L}$, albumin $3.1 \mathrm{~g} / \mathrm{L}$, globulin $7.6 \mathrm{~g} / \mathrm{L}$, serum LDH 299 IU/L, serum ALP: 789 IU/L, and uric acid $6.8 \mathrm{mg} / \mathrm{dL}$. Liver, kidney, and thyroid function tests were normal. Urine analysis revealed $\mathrm{pH}:$, density 1,025, protein 1+, leukocyte 2+, bilirubin, and glucose (-). Peripheral smear showed hypochromia, anisocytosis, and minimal poikilocytosis without atypical cells.

Due to the reduction of albumin/globulin ratio and symptomatic anemia, serum immunoglobulin profile was requested. Serum immunoglobulin profile revealed IgG: $6,190 \mathrm{mg} / \mathrm{dL}, \operatorname{IgM}: 10.2 \mathrm{mg} / \mathrm{dL}, \operatorname{IgA}$ : $9.59 \mathrm{mg} / \mathrm{dL}$, and IgE: $4 \mathrm{mg} / \mathrm{dL}$. Serum immunofixation test revealed monoclonal gammopathy (serum kappa light chain: $1,457 \mathrm{mg} / \mathrm{dL}$, serum lambda light chain: $183 \mathrm{mg} / \mathrm{dL}$ ). Then the patient's anamnesis was deepened, it was determined that there was a recurring back pain for the last one month in spite of analgesic treatment. Tumor invasion of the thoracic vertebra was detected in PET CT after the patient was diagnosed with breast cancer, but the lumbar vertebra was the usual appearance.

New lytic lesions that were not observed before chemotherapy was detected in a linear graph of lumbar vertebrae taken to illuminate the etiology of the patient's back pain. (L2-L4). On the initial assessment of the patient appeared to have hyponatremia, anemia, hypergammaglobulinemia, monoclonal gammopathy and lytic lesions on radiography. A full chemistry panel was significant for a prominent increase in the serum globulin and an elevated IgG. These aspects of her hyponatremia were highly suggestive for pseudohyponatremia to paraproteinemia.

Histopathologic examination of the bone marrow biopsy revealed CD138+ plasma cells with atypical morphology and tumor tissue with epithelial cells with large hyperchromatic nuclei (Figures 1-3). A presumptive diagnosis of simultaneously observed bone marrow involvement due to breast cancer and multiple myeloma was made. Hematology was consulted. A review of the pathology revealed multiple myeloma and the patient was referred to hematology clinic. The decision to treat this patient was based upon bone marrow involvement by atypical plasma cells, monoclonal gammopathy. The consultants on hematology recommended chemotherapy for multiple myeloma. The patient underwent nine cycles of bortezomib-dexamethasone treatment. Full remission was achieved.

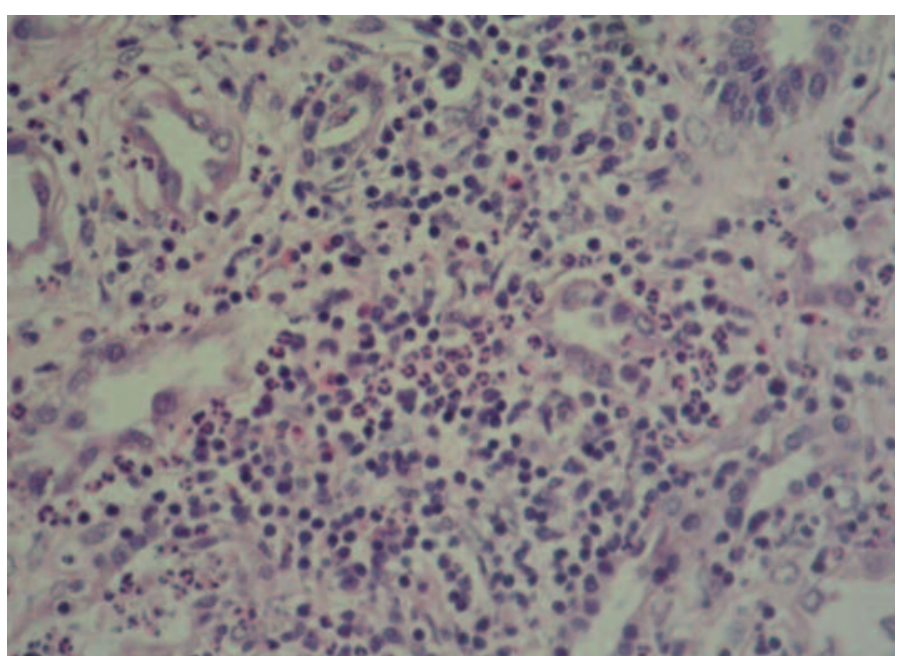

Figure 1. Areas of carcinoma in bone marrow by immunohistochemical test

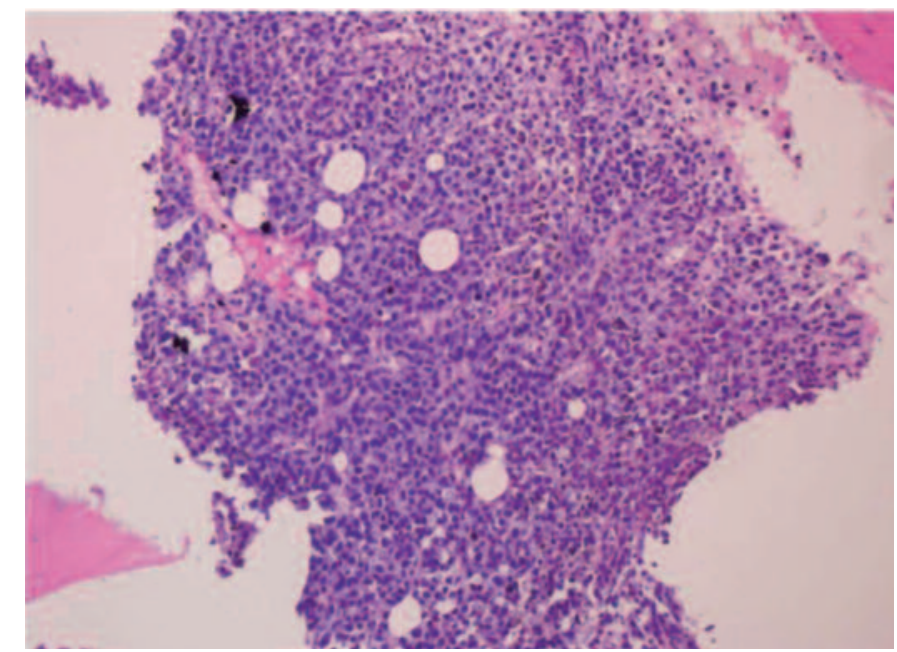

Figure 2. Plasma cells of multiple myeloma in bone marrow. $\mathrm{H} \& \mathrm{E} \times 200$

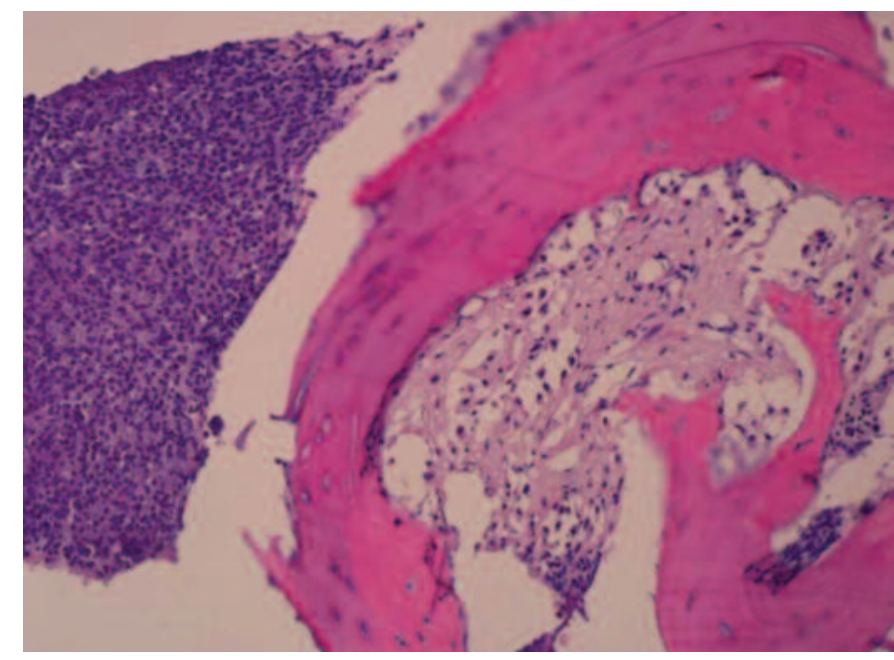

Figure 3. Plasma cells and areas of carcinoma in bone marrow. $\mathrm{H} \& \mathrm{E} \times 200$ 


\section{Discussion}

It is a rare situation to see multiple carcinomas in the same case. It is also very rare to see bone marrow involvement due to breast cancer and multiple myeloma in the same case.

Multiple primary carcinoma descriptions are provided with the following criteria: each malignant tumor must bear histological features; they must be different from each other histologically; exclusion must be done as they are not metastasis of each other [3].

The synchronous tumor is a situation when the diagnosis of a second tumor is established at the same time or in the following six months. If this rule is not provided, the second tumor is called as metachronous [4]. In our case also offered these three criteria, in addition to this, we evaluated as metachronous tumors in our study because multiple myeloma occurred one year after the diagnosis of breast cancer. Family history, genetic predisposition, previous chemotherapy and radiotherapy history are essential factors for various tumor developments [5]. We did not detect family history, radiotherapy history or a genetic mutation. She had received a chemotherapeutic regimen of cyclophosphamide, epirubicin, and 5fluorouracil. She received 11 cycles of this regimen. Plasma cell dyscrasia after chemotherapeutic regimen with alkylating chemotherapeutic agents especially like cyclophosphamide has been reported in the literature [6].

Multiple primary carcinoma cases were detected in $2.4 \%$ of 19,252 patients diagnosed with breast cancer in a study conducted in Italy [7]. Kılçıksız et al. [8] identified 297 primary tumor cases (1.47\%) among 20,290 cancer patients. This ratio was $1.74 \%$ in breast cancer cases $(38 / 2,186)$. It was reported that breast cancer could be associated with colon, vulva, lung, larynx, liver, and cancer of the cervix [2]. Although differences in the cases of breast cancer, multiple primary tumors are often seen in the elderly. Various primary tumors accompanying breast cancer are mostly seen in young ages and this rate decreases over 65 years of age [9]. Our patient was 49 years old, is compatible with this situation. Some previous case reports are showing the simultaneous existence of a solid tumor and multiple myeloma. The simultaneous presence of a solid tumor and multiple myeloma was reported as 3\% by Stegeman et al. [10]. Sakai et al. [11] reported an association between multiple myeloma with clear cell renal carcinoma and emphasized the possible role of growth factors like IL6. Kherfani et al. [12] reported a synchronous hormone receptor-positive breast cancer and multiple myeloma case with the involvement of thoracic and lumbar spinal cord. Sehgal et al. [13] reported a case of prostate adenocarcinoma and multiple myeloma with synchronous infiltration of bone marrow. Increased release of growth factors like IL-6, IGF-1 derived from multiple myeloma has been reported to trigger other malignancies. Demir et al. [14] reported a case of synchronous stomach adenocarcinoma and multiple myeloma.

\section{Conclusions}

The simultaneous existence of breast cancer and multiple myeloma are rarely reported. The presence of some laboratory signs and symptoms in patients with metastatic malignancy can be stimulating regarding synchronous or metachronous malignancies. Further studies are needed to determine the underlying etiologies and genetic factors in synchronous or metachronous malignancies.

\section{Informed consent}

Written informed consent was obtained from the patient's family for the publication of this case report.

\section{Conflict of interest}

The authors declared that there are no potential conflicts of interest with respect to the research, authorship, and/or publication of this article.

\section{References}

[1] Rajkumar SV. Multiple myelomas: 2011 update on diagnosis, riskstratification, and management. Am J Hematol 2011;8:57-65.

[2] Kalender ME, Sevinç A, Tutar E, Camcı C. [Synchronous renal cell carcinoma with medullary carcinoma of the breast]. Türk HematolojiOnkoloji Dergisi 2005;2:90-93. [Article in Turkish]

[3] Sarma M, Borde C, Subramanyam P, Shanmuga Sundaram P. Random synchronous malignancy in the male breast: a case report. J Breast Cancer 2013;16:442-6.

[4] Jiao F, Yao LJ, Zhou J, Hu H, Wang LW. Clinical features of multiple primary malignancies: a retrospective analysis of 72 Chinese patients. Asian Pac J Cancer Prev 2014; 15:331-4.

[5] Pastore AL, Palleschi G, Autieri D, Leto A, Ripoli A, Maggioni C, et al. Synchronous primary neoplasms of the bladder, skin and breast in a male patient: a case report. World J Surg Oncol 2013;11:282.

[6] Uğur MC, Ekinci F, Soyaltın UE, Özkan F, Atasoy I, Ceylan C, et al. [Waldenstrom case developed secondary to chemotherapy]. Tepecik Eğit Hast Derg 2014;24:131-3. [Article in Turkish]

[7] Eisinger F, Aubert L, Zanlucca S, Setz JF, Monges G, Sobol H, et al. [Synchronous cancers. A case with three localizations: rectal cancer 
associated with familial polyposis, breast cancer and adrenal gland cancer]. Presse Med 1995:24:1446. [article in French]

[8] Kılçıksız SÇ, Kaynak C, Eşki E, Yersal Ö, Ünlü İ, Çallı A, et al. [Evaluation of multiple primary tumors and single tumors charecteristics: a study from hospital-based cancer registry in İzmir]. Türk Onkoloji Dergisi 2007:22:55-62. [Article in Turkish]

[9] Buiatti E, Crocetti E, Acciai S, Gafa L, Falcini F, Milandri C, et al. Incidence of second primary cancers in three Italian population-based cancer registries. Eur J Cancer 1997:33:1829-34.

[10] Stegman R, Alexanian R. Solid tumors in multiple myeloma. Ann Intern Med 1979;90:780-2.

[11] Sakai A, Kawano M, Kuramoto A. Interleukin-6 produced by renal- cell carcinoma cells and progression of multiple myeloma. N Engl J Med 1991;324:1893-4.

[12] Kherfani A, Amri K, Hachem M, Abid L, Bouaziz M, Mestiri M. An association of vertebral breast cancer metastasis and multiple myeloma, revealed by a spinal cord compression. Pan Afr Med J 2014;19:168.

[13] Sehgal T, Sharma S, Naseem S, Varma N, Das A, Sharma SC. Synchronous occurrence of prostate carcinoma and multiple myeloma: a case report. Indian J Hematol Blood Transfus 2014;30(Suppl 1):35962.

[14] Demir C, Atmaca M, Tasdemir E, Efe S. Association of multiple myeloma and gastric adenocarcinoma. J Clin Exp Invest 2011;2:110-3. 